\title{
Enhanced and Impaired Attentional Performance After Infusion of D1 Dopaminergic Receptor Agents into Rat Prefrontal Cortex
}

\author{
Sylvie Granon, Filippo Passetti, Kerrie L. Thomas, Jeffrey W. Dalley, Barry J. Everitt, and Trevor W. Robbins \\ Department of Experimental Psychology, University of Cambridge, Cambridge CB2 3EB, United Kingdom
}

The role in spatial divided and sustained attention of D1 and D2-like dopamine (DA) receptors in the rat prelimbic medial prefrontal cortex (mPFC) was investigated in a five-choice serial reaction time task. Rats were trained to detect brief flashes of light $(0.5-0.25 \mathrm{sec})$ presented randomly in a spatial array of five apertures. When performance stabilized, animals received bilateral microinfusions of either the D1 DA receptor antagonist SCH 23390, the D1 DA receptor agonist SKF 38393, or the D2 $\mathrm{DA}$ antagonist sulpiride into the mPFC. Rats were divided into two groups, with low ( $<75 \%$ correct) and high $(>75 \%)$ baseline levels of accuracy. Infusions of the D2 receptor antagonist sulpiride had no significant effect on any task variable. $\mathrm{SCH}$ $23390(0.3 \mu \mathrm{g})$ selectively impaired the accuracy of attentional performance in rats in the high baseline condition. By contrast, SKF $38393(0.06 \mu \mathrm{g})$ enhanced the accuracy of attentional performance in the low baseline condition, a lower dose $(0.03$ $\mu \mathrm{g})$ also increasing the speed of making correct responses. Finally, the beneficial effects of SKF-383893 on choice accuracy were antagonized by $\mathrm{SCH} 23390(1.0 \mu \mathrm{g})$.

The results provide apparently the first demonstration of enhanced cognitive function after local administration of a D1 receptor agonist to the $\mathrm{MPFC}$ and suggest dissociable roles of D1 and D2 DA receptors of the MPFC in modulating attentional function.

Key words: prefrontal cortex; attention; dopamine; cognition; D1 receptor; D2 receptor; sulpiride; SKF 38393, SCH 23390
Cognitive functions of the prefrontal cortex are known to be modulated by ascending monoaminergic and cholinergic systems in rats and primates (Robbins et al., 1993; Muir et al., 1994; Granon et al., 1995; Arnsten 1997). Lesions of the mesocortical dopamine (DA) projection impair working memory performance in monkeys (Brozoski et al., 1979) and rats (Simon 1981). DA D1, but not D2, receptor antagonists impair working memory performance when infused into the primate sulcus principalis region (Sawaguchi and Goldman-Rakic, 1991) or into the rat prelimbic cortex (Seamans et al., 1998). These findings indicate that the D1 receptor has an important role in modulating cognitive performance under the control of the prefrontal cortex in both rat and monkey and are consistent with recent data showing beneficial effects of the mixed D1/D2 receptor agonist pergolide on a spatial working paradigm in humans (Muller et al., 1998).

Recent work has suggested that there is an optimal level of mesocortical DA function for mnemonic performance (Williams and Goldman-Rakic, 1995; Arnsten, 1997; Zahrt et al., 1997). There is evidence that elevations of cortical DA turnover, sometimes caused by stress or anxiogenic stimuli, are associated with impaired performance in delayed alternation procedures (Robbins, 1985; Sahakian et al., 1985; Murphy et al., 1996a,b; Arnsten, 1997) and that infusions of the DA D1 receptor agonist SKF 81297 actually impair delayed alternation performance in rats (Zahrt et al., 1997).

Received July 12, 1999; revised Oct. 25, 1999; accepted Nov. 8, 1999.

This work was supported by a Programme grant from the Wellcome Trust. It was completed within the Medical Research Council Cooperative in Brain, Behavior, and Neuropsychiatry. S.G. was supported by the Fyssen Foundation, the Simone and Cino DelDuca Foundation, and the Wellcome Trust.

Correspondence should be addressed to Trevor W. Robbins, Department of Experimental Psychology, Downing Street, Cambridge CB2 3EB, UK. E-mail: twr2@cus.cam.ac.uk.

Dr. Granon's present address: Laboratoire de Virologie Moléculaire, Institut Pasteur, 75015 Paris, France.

Copyright (C) 2000 Society for Neuroscience $\quad 0270-6474 / 00 / 201208-08 \$ 15.00 / 0$
Other aspects of cognitive function besides working memory have been less extensively studied and might be differentially affected by fluctuations in prefrontal DA function (Roberts et al., 1994; Collins et al., 1998). Therefore, we examined effects of manipulations of prefrontal dopamine on attentional function in rats. We used the five-choice serial reaction time task (Robbins, 1998), which requires rats to divide attention on a sustained basis via visual search to detect brief visual target stimuli presented randomly in one of five locations in a spatial array. Previous results have indicated dissociable effects after lesions to central noradrenergic and serotoninergic systems, as well as to the basal forebrain cholinergic system and the mesolimbic and mesostriatal DA systems (Robbins and Everitt, 1995). Excitotoxic lesions of the prelimbic prefrontal, but not the cingulate or parietal, cortex (Muir et al., 1996) impair accuracy of performance on this task, as does prefrontal cholinergic depletion effected by excitotoxic lesions of the basal forebrain (Muir et al., 1994). However, the possible contribution of prefrontal DA function to these effects remains unclear and so in this study we examined the role of D1 and D2 DA receptors of the rat medial prefrontal cortex (mPFC) by infusing specific agents there. By taking account of individual variability in attaining stable performance and varying the difficulty of the discrimination we examined the possibility of improved, as well as impaired, attentional performance as a function of the behavioral baseline. We also included several controls to assess the neuroanatomical, as well as the neuropsychological and neuropharmacological specificity of the effects.

\section{MATERIALS AND METHODS}

Subjects. The subjects were male Lister hooded rats (Charles River) weighing between 300 and $380 \mathrm{gm}$ before surgery. They were housed in pairs until surgery and then alone under temperature-controlled conditions and an alternating light/dark cycle (lights on from 7:00 A.M. to 7:00 P.M.). All rats were given ad libitum access to water and were maintained between 80 and $90 \%$ of their free-feeding weight by providing 15-20 gm 
of laboratory chow once daily. Rats were tested 5-6 d/week. The experiments were performed under UK Home Office Project license number 80/00684, according to the UK Laboratory Animals Act of 1986.

Surgery. Rats that had previously been trained to a stable level of performance (see below) were anesthetized with Avertin (2\% 2,2,2tribromoethanol, $1 \%$ 2-methylbutan-2-ol, and $8 \%$ ethanol in $0.01 \mathrm{M}$ PBS, $\mathrm{pH} 7.2,10 \mathrm{ml} / \mathrm{kg}$ i.p.). Twenty-two gauge stainless-steel guide cannulas were implanted into the prelimbic area of the prefrontal cortex using standard stereotaxic techniques. The stereotaxic coordinates (flat skull) were derived from Paxinos and Watson (1982): anteroposterior (AP), $+3.2 \mathrm{~mm}$ from bregma; lateral (L), $\pm 0.6 \mathrm{~mm}$ from midline; dorsoventral (DV), $-2.0 \mathrm{~mm}$ from the skull. Twenty-nine gauge stylets flush with the end of the guide cannulas remained in place until the injections were made.

Apparatus. Eight $25 \times 25 \mathrm{~cm}$ nine-hole Plexiglas and aluminum boxes (Paul Fray Ltd, Cambridge, UK) were used. Detailed descriptions of the apparatus and the experimental procedures have been provided elsewhere (Carli et al., 1983). Briefly, each box was inserted in a soundproof chamber and illuminated in the roof with a $3 \mathrm{~W}$ bulb. In the rear wall of the chamber were five apertures with an infrared photocell beam crossing the entrance to detect nosepoke responses and a $3 \mathrm{~W}$ bulb located at the rear to provide visual target stimuli, respectively. At the front wall, a magazine connected with a food pellet dispenser was present with access provided by pushing a Perspex panel. The eight boxes were controlled by two Archimedes computers and software provided by CeNeS (Cambridge, UK).

Behavioral procedure. Food-deprived rats were trained to perform the five-choice serial reaction time task, as described elsewhere (Carli et al., 1983). After pretraining, rats were trained to detect brief flashes of light $(0.5 \mathrm{sec})$ presented randomly in the spatial array of five apertures. After the light flash, rats had to make a nosepoke response in the hole where the light had been presented to obtain food reward in the food magazine at the front of the chamber. The rats were required to push the food panel to gain access to the food pellet (Noyes dustless pellets, $45 \mathrm{mg}$; Sandown Scientific). The next trial followed after an intertrial interval (ITI) of $5 \mathrm{sec}$. Incorrect responses at apertures where the light had not been presented (errors of commission), failures to detect the stimuli in a $5 \mathrm{sec}$ period after its presentation, or premature responses at the apertures in the intertrial intervals, were all punished with brief periods of time-out (darkness). In the case of incorrect responses, rats were still required to initiate the next trial with the same panel push response at the food magazine. A session consisted of 100 trials or was 30 min long. Rats were taken for surgery when stable performance (performance accuracy, $<5 \%$ variation from the running mean over five consecutive sessions) had been attained, typically after $\sim 30$ sessions. After 1 week of recovery, rats were retrained. Rats were divided into two subgroups, based on their capacity to maintain stable levels of performance. To achieve this separation, some rats were maintained at the preoperative stimulus duration (i.e., $0.5 \mathrm{sec})$; this included some rats $(n=4)$ performing stably at a relatively lower level of accuracy (mean accuracy consistently $<75 \%)$ than that typically attained by the majority $(>75 \%$ correct). In another group of rats that had stabilized $>75 \%$ correct, the stimulus duration was gradually reduced (never below $0.25 \mathrm{sec}$ ) over $\sim 10$ further sessions. Rats that could not sustain stable performance over three sessions at these shorter durations were restabilized at $0.5 \mathrm{sec}$. The division of the rats into the two subgroups was thus based on the average levels of accuracy maintained, irrespective of the actual stimulus duration used (between 0.25 and $0.5 \mathrm{sec}$ ). There were 27 rats in the low baseline condition and 33 in the high baseline condition. The low and high baseline groups were actually well-matched in terms of the average stimulus duration used: low, $0.317 \pm 0.019 \mathrm{sec}$; high, $0.327 \pm 0.020 \mathrm{sec}$; $t=0.4 ; p>0.7$. This matching was also maintained in the smaller subgroups used for particular pharmacological challenges across the four experiments; there were no significant differences for any such pair of subgroups.

Microinfusion procedure. Rats were tested in groups of 6-10. A sham inf usion always preceded the beginning of the experiment. On infusion days, rats were gently restrained, the stylets were removed, and 30 gauge stainless steel double injectors extending $1.5 \mathrm{~mm}$ beyond the tip of the cannula were inserted. The drugs were administered in a volume of $0.5 \mu \mathrm{l}$ at a rate of $0.5 \mu \mathrm{l} / 2 \mathrm{~min}$ by a Harvard Apparatus microsyringe pump. Injectors were left in place for 2 min to allow for diffusion. Each rat was then placed immediately into the experimental chamber. At least 3 and generally $4 \mathrm{~d}$ separated each test day, and rats were always tested behaviorally on at least $2 \mathrm{~d}$ before infusion to re-establish the baseline and thus monitor the possibility of permanent damage produced by the infusions (lesions of the rat medial prefrontal cortex produce lasting deficits in choice accuracy; Muir et al., 1996).

Experimental design. Rats were assigned to groups on the basis described below. In microinf usion studies using large numbers of rats such as this it is necessary gradually to accumulate the subjects in sufficient numbers in different cohorts. To clarify the presentation and analysis of results, the following assignations to the experimental groups were made. Each dose of drug was analyzed separately by subgroup ("low" or "high" baseline) because not all rats received all doses of the drugs. No rat received more than six intracerebral infusions.

In experiment 1, 16 rats (12 low, 4 high) were used for the SKF 38393 $(0.03 \mu \mathrm{g})$ study. For the $0.06 \mu \mathrm{g}$ dose of SKF 38393, 23 rats were used (9 low and 14 high). Four of these rats also received $0.03 \mu \mathrm{g}$ SKF 38393 and were also included in that group.

In experiment 2, $(\mathrm{SCH} 23390,0.3 \mu \mathrm{g}) 24$ rats were used (13 low, 11 high). Thirteen rats ( 5 low, 8 high) received only counterbalanced bilateral inf usions of the vehicle control and different doses of SCH $23390(0.3$ $\mu \mathrm{g}$ and either 0.1 or $3.0 \mu \mathrm{g}$, not reported here). Of the other $11 \mathrm{rats}, 7 \mathrm{had}$ also received a dose of $0.06 \mu \mathrm{g}$ SKF 38393 alone (from experiment 1, above).

In experiment 3, 15 (5 low, 10 high) of the rats used for the $0.06 \mu \mathrm{g}$ dose of SKF 38393 (experiment 1, above) also received counterbalanced bilateral infusions of SCH 23390, $1 \mu \mathrm{g}$ side alone and in combination with $0.06 \mu \mathrm{g}$ SKF 38393.

In experiment 4, 12 rats received a dose of $1 \mu \mathrm{g}$ sulpiride and 9 of these also received $3 \mu \mathrm{g}$ in a counterbalanced sequence with control vehicle infusions. Eight of the rats were in the high baseline subgroup and 4 in the low baseline subgroup.

Drugs. SCH 23390, SKF 38393 and sulpiride were all purchased from Research Biochemicals (Natick, MA). All drugs were freshly dissolved in saline solution which was adjusted to $\mathrm{pH}$ 5.5-6.0 immediately before infusion.

Behavioral variables and data analysis. Several variables were monitored: accuracy (the percentage of correct completed responses, i.e., correct/correct + errors of commission $\times 100$ ), errors of omission, and the latency (to the nearest $0.01 \mathrm{sec}$ ) for correct responses. These measures were statistically analyzed using ANOVA and appropriate methods of post hoc analysis. Separate two-way ANOVAs were used with one between-subjects (baseline) and one within-subjects factor (dose, drug vs control) for each dose infused. It was not feasible to analyze all of the data in an overall ANOVA because not all rats had received each dose of a particular drug.

Histology. After completion of the behavioral testing, rats were killed by lethal Nembutal injection and perfused transcardially. Brains were removed and fixed in $10 \%$ formalin solution. The brains were frozen and sliced in $40 \mu \mathrm{m}$ sections before mounting and Nissl staining with cresyl violet. Inspection of the cresyl-stained slides under the light microscope and the trajectory of gliosis produced by the cannula allowed its location and tip to be estimated and mapped onto sections prepared from the Paxinos and Watson (1982) atlas (Fig. 1). Data from six animals in which one or both of the cannulas were misplaced were excluded from the subsequent analyses and are not included in the numbers of rats used in each experiment, above.

To assess the likely extent of diffusion of the drugs over time, $0.5 \mu 1$ $(0.003 \mu \mathrm{g})$ of $\left[N\right.$-Methyl- $\left.{ }^{3} \mathrm{H}\right] \mathrm{SCH} 23390$ (Amersham International UK) were injected over $2 \mathrm{~min}$ into each side of the prefrontal cortex through the guide cannulas in three additional anesthetized rats. Five or $60 \mathrm{~min}$ later the rats were overdosed without recovery, and the brains removed and rapidly fresh frozen. Twenty micrometer sections were cut on a cryostat and serially thaw-mounted onto gelatin-coated glass slides. Slides were air-dried and opposed to tritium-sensitive film (Hyperfilm; Amersham International UK) along with tritiated polymer standards (Microscales; Amersham International UK) for between 2 and 4 weeks. Films were developed using Kodak (Eastman Kodak, Rochester, NY) D19 and fixed in Kodak Unifix.

The area of diffusion and densitometric analyses of radioligand binding in the tissue were carried out on sections taken at AP levels +4.0 to $+2.0 \mathrm{~mm}$ (Paxinos and Watson, 1982). The area of radioactive signal and the concentration of radioactivity on the autoradiographs was measured using the Openlab package from Improvision. The regional film densities were converted to ligand concentration by reference to the tritiated standards on the same film. 


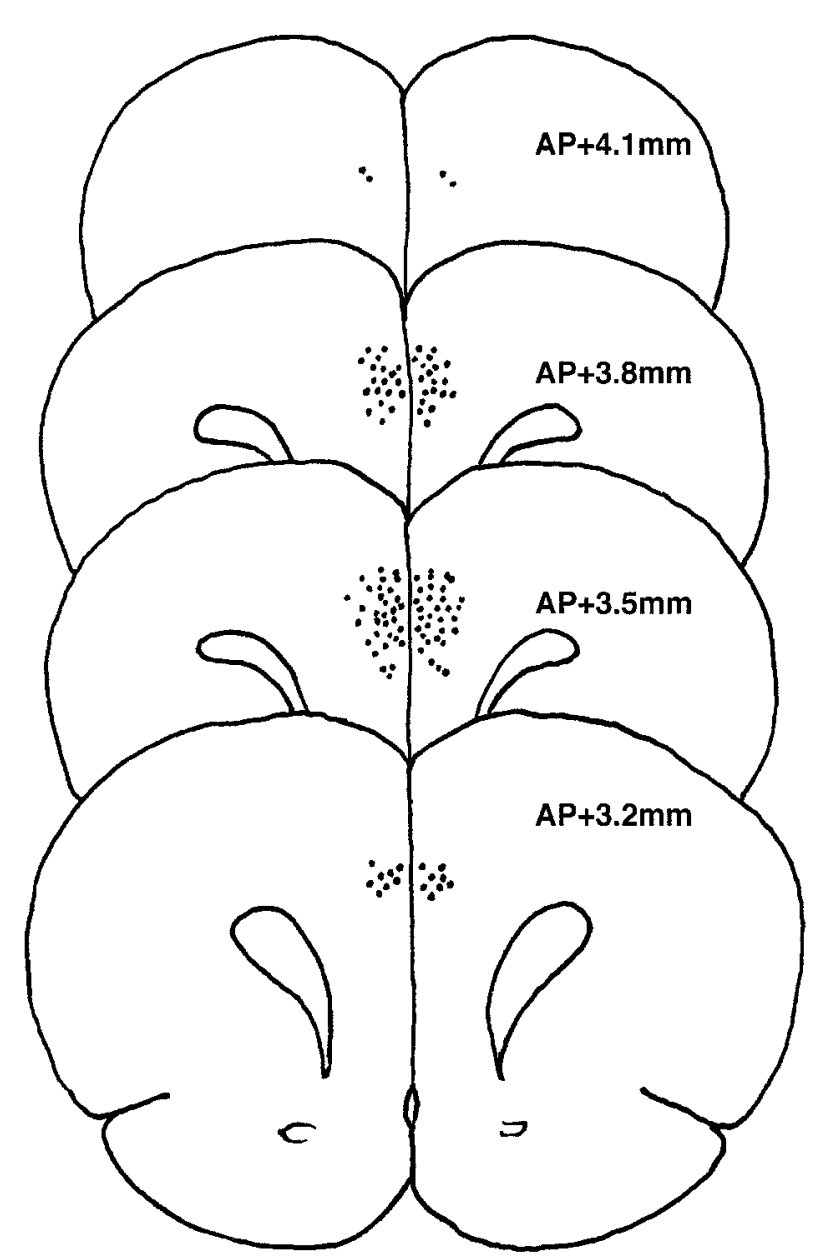

Figure 1. Histological reconstruction of cannulation sites for experiments $1-4, n=60$.

\section{RESULTS}

\section{Histology}

Figure 1 shows a schematic diagram of the position of cannula tips immediately dorsal to the rat prelimbic area. The total number of animals included from the four behavioral experiments was 60 .

\section{Control for spread}

The diffusion of the D1 receptor antagonist [ $N$-Methyl- $\left.{ }^{3} \mathrm{H}\right] \mathrm{SCH}$ 23390 was largely limited to the infusion site in the dorsal prelimbic cortex 5 and 60 min later (Fig. $2 A$ ) with some spread into the anterior cingulate cortex. The concentration and area of radioligand diffusion was maximal around the infusion site (Fig. $2 B$ ). In no case was there any diffusion ventrally across the corpus callosum into the head and body of the caudate putamen (below AP level, +2.0, data not shown). In general, the area of diffusion was smaller at $5 \mathrm{~min}$ than at $60 \mathrm{~min}$ after infusion at all rostrocaudal levels, but the concentration of SCH 23390 was greater at 5 min than at 60 min after infusion. Nevertheless, there was a substantial amount of SCH 23390 remaining in the vicinity of the infusion site even after $1 \mathrm{hr}$.

\section{Experiment 1: baseline-dependent effects of intra-mPFC} infusion of the DA D1 receptor agonist SKF 38393

Thirty-five animals trained to detect brief visual stimuli in the five-choice serial reaction time task were assigned to two different groups according to their baseline performance, low baseline with accuracy $<75 \%$; and high baseline with accuracy $>75 \%$ correct. Sixteen of these animals received bilateral intra-mPFC infusions of either vehicle or $0.03 \mu \mathrm{g} /$ side SKF-383893.There was no significant effect of dose $\left(F_{(1,14)}=1.59\right)$ or of the dose $\times$ baseline interaction $\left(F_{(1,14)}=3.14 ; p=0.098\right)$, despite the evident tendency shown in Table 1 for the low baseline condition to show some improvement. This dose also had no effect on omissions $\left(F_{(1,14)}=1.53\right)$, but did speed latency in a way that depended on the baseline level of accuracy (dose $\times$ baseline interaction, $\left.F_{(1,14)}=5.2 ; p=0.039\right)$. As can be seen from Table 1 , SKF 38393 more effectively speeded performance in the low baseline group.

Twenty-three animals (including four also tested with $0.03 \mu \mathrm{g}$ SKF 38393) were tested with $0.06 \mu \mathrm{g} /$ side of SKF 38393, which produced significant, baseline-dependent improvements in accuracy (Fig. $3 A$ ). ANOVA of the percentage of correct responses revealed a significant dose effect $\left(F_{(1,21)}=15.8 ; p<0.01\right)$ and a significant dose $\times$ baseline interaction $\left(F_{(1,21)}=16.3 ; p<0.01\right)$. Post hoc analysis showed a significant effect of dose for animals of the low baseline group $\left(F_{(1,8)}=27.8 ; p<0.01\right)$, but not for animals performing at high baseline levels of accuracy, $(p>0.05)$ (Fig. 3B). These results suggest that SKF 38393 mainly improved performance of the five-choice serial reaction time task when animals were performing at a low level of choice accuracy. There was also a parallel, but weaker, effect to reduce omissions (dose $\times$ baseline interaction, $\left.F_{(1,21)}=0.047\right)$. No other measure of performance was affected by infusion of this dose (Table 2).

Experiment 2: baseline-dependent effects of intra-mPFC infusion of the DA D1 receptor antagonist SCH 23390

Twenty-four animals were divided into two groups according to their baseline level of performance: low baseline performance $(n=13)$, with mean accuracy $<75 \%$; and high baseline performance $(n=11)$, with mean accuracy $>75 \%$. When tested with intra-mPFC inf usion of $0.3 \mu \mathrm{g} /$ side SCH 23390, ANOVA for the percentage of correct responses showed a significant dose effect $\left(F_{(1,22)}=5.8 ; p=0.024\right)$ and a significant interaction between drug and baseline treatment $\left(F_{(1,22)}=10.0 ; p<0.01\right)$ (Fig. 3B). Post hoc analysis revealed a dose effect for the high baseline performance group $\left(F_{(1,10)}=9.7 ; p=0.011\right)$, but not for the low baseline performance group, $p>0.05$ ). No significant effect was found on other measures of performance, such as percentage of omissions or mean correct latency (Table 2). These results suggest that the effect of SCH 23390 depended on the subjects' baseline level of performance, with high performers (but not rats performing at a lower level of accuracy) being impaired by the drug.

\section{Experiment 3: antagonism of effects of SKF 38393 by SCH} 23390 co-infusions into mPFC (Table 3)

Fifteen of the animals treated with $0.06 \mu \mathrm{g}$ SKF 38393 also received bilateral infusions of $1 \mu \mathrm{g} /$ side of SCH 23390, and a combination of $1 \mu \mathrm{g} \mathrm{SCH} 23390 /$ side $+0.06 \mu \mathrm{g}$ SKF 38393/side, all in a counterbalanced sequence. This was a subset of rats from experiment 1 reported above. The dose of SCH 23390 was chosen because a preliminary experiment demonstrated that $0.3 \mu \mathrm{g}$ was ineffective in blocking the effects of either 0.03 or $0.06 \mu \mathrm{g}$ SKF 38393. In this subset of the rats from experiment 1, SKF 38393 still significantly improved choice accuracy, as revealed by a significant dose effect $\left(F_{(1,13)}=8.5 ; p=0.012\right)$. ANOVA of the 
A.

5 min.

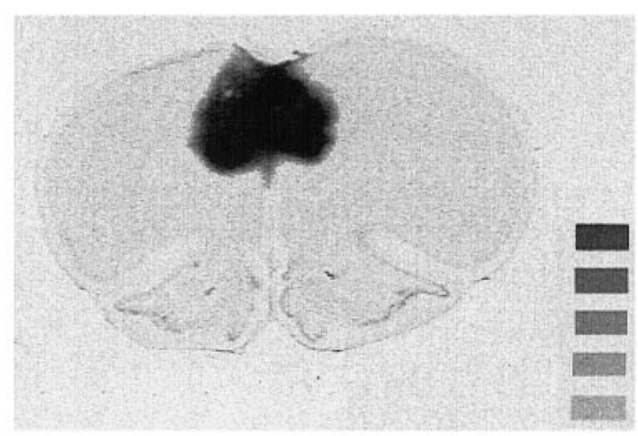

B.

\section{Area of Diffusion of ${ }^{3} \mathrm{H}-\mathrm{SCH} 23390$}

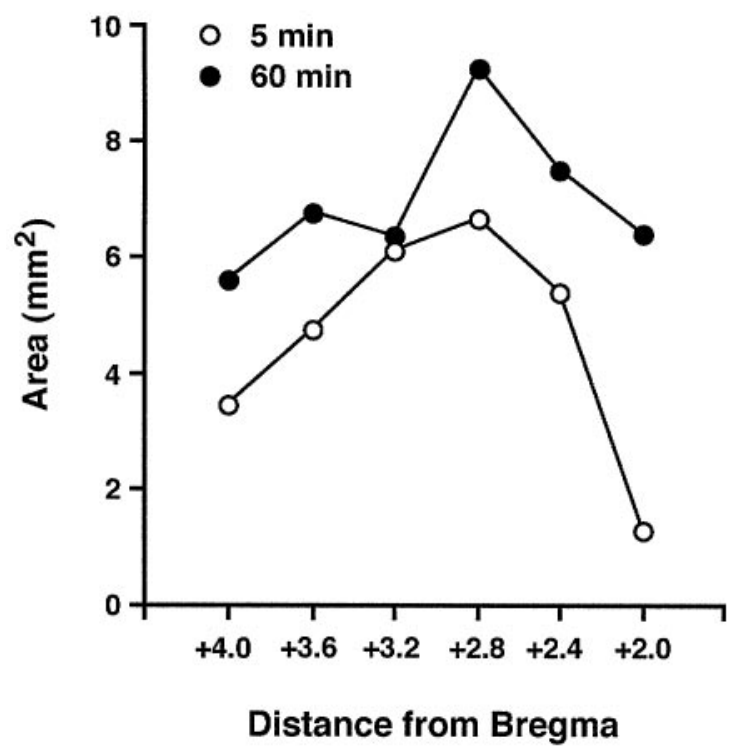

$60 \mathrm{~min}$.

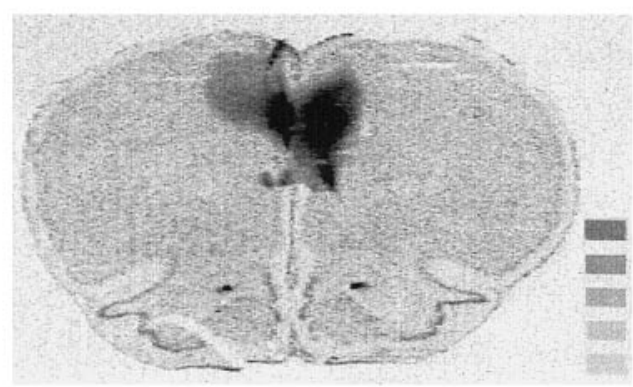

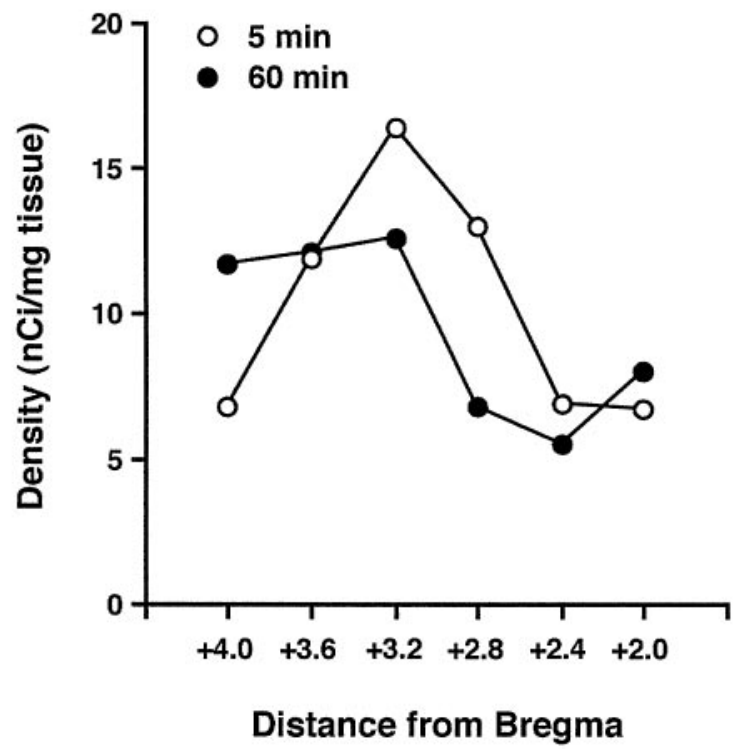

Figure 2. A, Composite images in individual $20 \mu \mathrm{m}$ coronal sections of a rat brain of the autoradiographic signal 5 or 60 min after bilateral infusion of $0.003 \mu \mathrm{g}$ [N-Methyl- $\left.{ }^{3} \mathrm{H}\right] \mathrm{SCH} 23390$ into the frontal cortex overlaid onto the corresponding Nissl-stained section. The sections were taken at approximately AP +3.2. The highest densities (greatest blackness) of radioactive binding in the tissue were confined to the prelimbic and anterior cortices. The density of radioligand binding was assessed from the autoradiographs by reference to radioactive microscale standards, shown in the bottom right-hand corner of each panel. Activities from the most to the least black standard (in nanocuries per milligram tissue): 17.42, 10.26, 7.08, 4.28, and 2.49. $B$, The area of diffusion and concentration of radioactivity at different rostrocaudal levels 5 and $60 \mathrm{~min}$ after inf usion of $0.003 \mu \mathrm{g}\left[N-\mathrm{Methyl}-{ }^{3} \mathrm{H}\right] \mathrm{SCH}$ 23390 into the rat frontal cortex. Autoradiographs were analyzed using a microcomputer-based image analyzer. Areas were assessed with reference to an external linear measurement, and concentration values were measured with reference to radioactive microscale standards opposed to the same film. Data from three individual rats at each time point are presented. The concentration and area of radioligand diff usion was maximal around the inf usion site. Statistical analysis revealed that for the density of bound radioactive SCH-23390, there was a significant distance $\times$ time after infusion interaction after ANOVA $\left(F_{(2,29)}=5.18 ; p<0.05\right)$, whereas for the area of diffusion of the radiolabeled receptor antagonist, there was a trend for a distance $\times$ time interaction $\left(F_{(2,29)}=3.26 ; p=0.053\right)$. Data are presented from three individual rats at each time point.

percentage of correct responses also revealed a significant dose $\times$ baseline interaction $\left(F_{(1,13)}=15.1 ; p<0.01\right)$. However, $1 \mu \mathrm{g} / \mathrm{side}$ SCH 23390 blocked the improvement of choice accuracy induced by the D1 agonist: ANOVA of the percentage of correct responses found no significant effect of the infusion of the combination of SCH $23390+\operatorname{SKF} 38393\left(F_{(1,13)}=0.1\right.$; NS) or drug $\times$ baseline interaction $\left(F_{(1,13)}=2.1\right.$; NS). Intra-mPFC infusion of 1 $\mu \mathrm{g} /$ side SCH 23390 alone had no effect on choice accuracy. ANOVA found no significant drug $\left(F_{(1,13)}=2.7\right.$; NS) nor a drug $\times$ baseline interaction $\left(F_{(1,13)}=0.1\right.$; NS) for this infusion. No other measure of performance was affected by any of the treatments (Table 3). 
Table 1. Behavioral effects of intra-mPFC SKF $38393(0.03 \mu \mathrm{g} /$ side $)$ on a five-choice serial reaction time task

\begin{tabular}{llccl} 
& & \% Correct & \% Omissions & Latency correct $(\mathrm{sec})$ \\
\hline Low baseline & Control vehicle & $68.7 \pm 1.2$ & $14.0 \pm 2.6$ & $0.76 \pm 0.04$ \\
$(n=12)$ & SKF 38393 $(0.03 \mu \mathrm{g} /$ side $)$ & $76.1 \pm 2.4$ & $9.2 \pm 2.0$ & $0.61 \pm 0.03^{*}$ \\
High baseline & Control vehicle & $81.5 \pm 2.4$ & $10.7 \pm 7.4$ & $0.44 \pm 0.01$ \\
$(n=4)$ & SKF 38393 $(0.03 \mu \mathrm{g} / \mathrm{side})$ & $80.2 \pm 5.4$ & $9.5 \pm 1.5$ & $0.54 \pm 0.09$ \\
\hline
\end{tabular}

Mean \pm SEM values are shown

*Indicates a significant difference compared to control vehicle $(p<0.05)$.

\section{Experiment 4: effects of intra-mPFC infusion of the D2 receptor antagonist sulpiride}

Rats received intracerebral infusion of sulpiride ( 1 or $3 \mu \mathrm{g} / \mathrm{side}$ ) or of saline in a counterbalanced order (Table 4). For the accuracy measure (percentage correct), there was no effect of dose $\left(F_{(2,20)}=0.1 ; \mathrm{NS}\right)$, and the dose $\times$ baseline interaction term was also not significant $\left(F_{(2,20)}=2.06 ; p=0.154\right)$. Table 4 shows that, for the most relevant comparison with $0.3 \mu \mathrm{g} \mathrm{SCH} 23390$ (which impaired accuracy in the high baseline conditions), there was no effect of either 1 or $3 \mu \mathrm{g}$ of sulpiride. Neither omissions nor latency measures were affected by sulpiride either as main effects $\left(F_{(2,20)}<1.0 ; \mathrm{NS}, 2.79 ; p=0.09\right.$, respectively) or interacting with baseline (both $F_{(2,20)}<1.0$, NS). As can be seen from Table 4, there was a nonsignificant tendency for $3 \mu \mathrm{g}$ to speed responding, again in contrast to the effects of SCH 23390.

\section{DISCUSSION}

The main findings of this study were that the DA agonist SKF 38393 produced baseline-dependent improvements in rats' performance on the five-choice attentional task when infused into the prelimbic frontal cortex. To our knowledge this is the first report of beneficial effects on behavioral performance produced by direct manipulations of prefrontal dopamine function in intact animals. The most striking effect was on the accuracy of attentional performance, which was enhanced at the $0.06 \mu \mathrm{g} / \mathrm{side}$ dose of the DA agonist. Although there was an overall effect of the drug to improve performance regardless of baseline condition, the improvement was largely restricted to the low ( $\sim 70 \%$ correct) baseline accuracy condition. This dose of the D1 agonist also reduced errors of omission, but did not affect response latency. By contrast, the lower dose $(0.03 \mu \mathrm{g})$ had no significant effect on accuracy but did speed correct responses in the low baseline accuracy condition. Overall, these improvements in performance following SKF 38393 appear to have considerable behavioral specificity.

In contrast to the beneficial effects of the D1 agonist, intracortical infusions of $0.3 \mu \mathrm{g}$ of the D1 antagonist SCH 23390 produced an apparently selective impairment of performance accuracy. This effect was largely seen in rats performing at a high, but not at a lower, baseline. Consequently, it appears that performance on this attentional task can be modulated in normal rats by activity at the DA D1 receptor under certain conditions. There were no significant effects on other aspects of performance at this dose, suggesting that the impaired accuracy was unlikely to have arisen simply from actions of the drug on motor function, which would have been expected to retard response latencies or increase errors of omission. Preliminary experiments (Robbins et al., 1998) had established that the $0.3 \mu \mathrm{g}$ dose was optimal for detecting task-related impairments in accuracy, and it is indeed similar to the range used by Seamans et al. (1998) to produce impairments of working memory performance in rats $(0.5-5.0$ $\mu \mathrm{g})$. Surprisingly, the higher dose $(1 \mu \mathrm{g})$ failed to impair accuracy significantly at high or low baselines of performance, possibly as a result of a tendency to reduce the number of trials completed, but also conceivably because of nonselective actions at, for example, the 5-HT2 receptor (Ohlstein and Berkowitz, 1985). There is also evidence that systemic or intracortical infusions of 5-HT2 receptor antagonists increase cortical DA release (Schmidt and Fadayel, 1995; Pehek 1996; Pehek and Bi, 1997; Millan et al., 1998), which may functionally oppose the effects of D1 receptor blockade.

The facilitatory effects of SKF 38393 on accuracy in the fivechoice task were completely blocked by SCH $23390(1 \mu \mathrm{g})$, although we found no evidence that a lower dose of $0.3 \mu \mathrm{g} \mathrm{SCH}$ 23390 was effective against either $0.3 \mu \mathrm{g}$ or $0.06 \mu \mathrm{g}$ SKF 38393 (data not reported). Because some of the oral motor effects of SKF 38393 can be blocked by intrastriatal infusions of the 5-HT2 receptor antagonist mianserin (Plech et al., 1995) and because SKF 38393 binds with low affinity to the 5-HT1C (now reclassified as 2C) receptor (Briggs et al., 1991), it is just possible that its facilitatory effects on performance are mediated by 5-HT2 receptors. However, the motor behavioral effects of SKF 38393 are not blocked by the 5-HT2A/C receptor antagonist ketanserin (Gong et al., 1992). Consequently, the complete blockade of the effects of SKF 38393 on response accuracy by SCH 23390, even despite its 5-HT2A receptor blocking properties (Bischoff et al., 1988) and its 5-HT2C agonist effects (Briggs et al., 1991), most parsimoniously implicates cortical D1 receptors. Further evidence for the importance of the D1 receptor derives from the observations (experiment 4) that the impairment produced by SCH 23390 at $0.3 \mu \mathrm{g}$ could not be mimicked by infusions of the selective DA D2 receptor antagonist sulpiride. However, some modulation of performance by DA D2 receptors cannot completely be excluded.

We performed several controls to ensure that the main locus of the drug effect was within the prelimbic prefrontal cortex. The sites of infusion were quite highly localized to dorsomedial prelimbic cortex (Fig. 1). Moreover, Figure 2 shows that spread was generally restricted to the medial prefrontal region. We assume that similar gross effects would have been found with sulpiride and SKF 38393, although the distribution of these compounds might have been affected by their degree of lipophilicity. The volumes infused of these agents were similar to those used by other authors (Zahrt et al., 1997; Seamans et al., 1998). Although we have not presented the detailed time course of action in the attentional task, most of the effects described were relatively constant over the four blocks of the task, which generally lasted for $\sim 30 \mathrm{~min}$. Manipulation of prefrontal DA function can have repercussions on subcortical systems, for example in the striatum (Roberts et al., 1994; Vezina et al., 1994), but these are generally 
A.

Effect of $0.06 \mu \mathrm{g}$ SFK 38393 on Accuracy

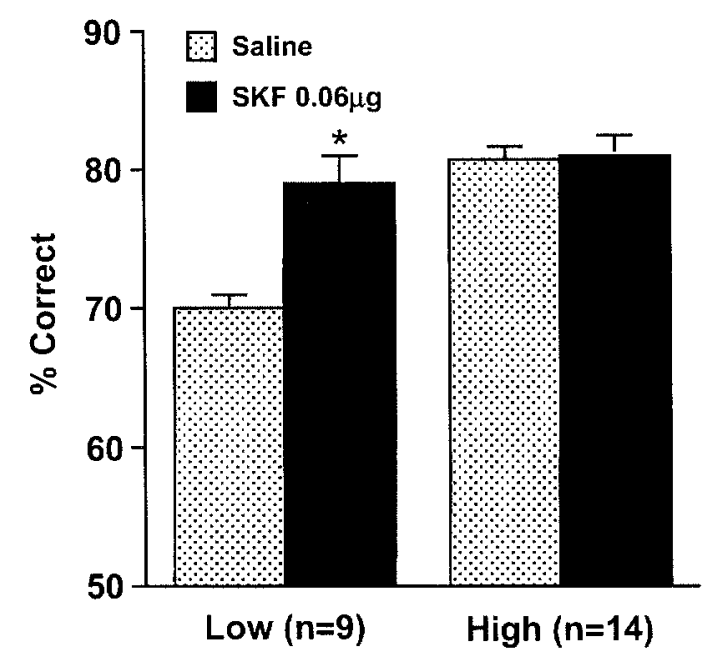

Baseline Performance

B.

\section{Effect of $0.3 \mu \mathrm{g} \mathrm{SCH} 23390$ on Accuracy}

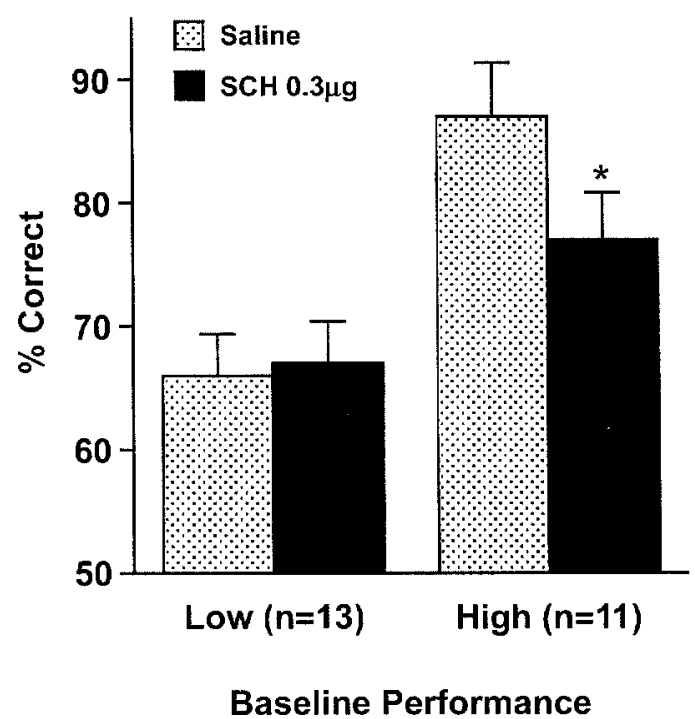

Figure 3. A, Baseline-dependent effects of SKF $38393(0.06 \mu \mathrm{g})$ on accuracy of performance in the five-choice serial reaction task after bilateral prefrontal cortical infusions. $B$, Baseline-dependent effects of SCH $23390(0.3 \mu \mathrm{g})$ on accuracy of performance in the five-choice serial reaction task after bilateral prefrontal cortical infusions.

delayed (Duvauchelle et al., 1998) and therefore unlikely to have affected performance here, especially in view of the spacing of infusions over days and the provision of control test sessions to ensure that performance had reached baseline before each infusion. Moreover, manipulations of ventral striatal dopamine in the five-choice task have no effect on accuracy (Cole and Robbins, 1989), and dorsal striatal dopamine depletion only impairs accu- racy when the signals are temporally unpredictable (Baunez and Robbins, 1999).

The results do not contradict the hypothesis that there is a U-shaped function relating efficiency of cognitive performance (Zahrt et al., 1997; Arnsten, 1998) to the level of stimulation of the D1 receptor. However, evidence for this hypothesis in those studies derives from observations that performance in a working memory task could be impaired by intracortically infused D1 agonists and from the antagonism of this effect by a systemic DA receptor antagonist. In this study, we have shown that small doses of a D1 agonist can improve performance, mainly when it is degraded to lower levels, usually as a consequence of individual differences among the rats in response to manipulation of stimulus duration. The implication is that in the rats with lower baselines of performance, activity within the mesocortical DA system is suboptimal and so can be boosted by the D1 agonist close to normal optimal levels. By contrast, in rats with superior performance, the mesofrontal DA system may be more "engaged" by the task and thus more susceptible to DA receptor blockade by SCH 23390. How D1 receptor agonist treatment might modulate lower levels of performance produced specifically by manipulations of specific task parameters to affect different cognitive components of performance must be addressed by further research.

These data are theoretically important in showing that factors determining the baseline level of performance (including individual differences) can be a determining feature of whether the inf used agonist produces improvement or deleterious effects. The deleterious effects of D1 agonists in other studies (Zahrt et al., 1997; Arnsten, 1998) might also have depended on the nature of the cognitive process under test. Indeed, recent evidence (Roberts et al., 1994; Collins et al., 1998) showed that effects of prefrontal cortical dopamine depletion differed in monkeys according to whether the measure of prefrontal dysfunction was spatial working memory, response sequencing, or attentional setshifting. Thus, there may be different optimum levels of dopamine function for different forms of cognitive processing in the prefrontal cortex. Another potential difference between this study and that of Zahrt et al. (1997) is the use of a partial D1 agonist here, rather than a full D1 receptor agonist. On the other hand, Arnsten et al. (1994) have reported significant improvements in working memory performance after systemic treatment of intact young monkeys with a full D1-receptor agonist, which shows that enhancement of normal cognitive performance is a plausible consequence of treatment with D1 agents, possibly at sites including the PFC.

The present results are compatible with a hypothesized mechanism by which one consequence of the effects of DA or DA agonists is to "sharpen" NMDA receptor-mediated and other depolarizing synaptic signals arriving on apical dendrites. This is postulated to occur by attenuation of high threshold calcium spikes that amplify signals propagating along the dendrite to reach the soma within the prefrontal cortex (Yang and Seamans, 1996; Zahrt et al., 1997, their Fig. 6; Seamans et al., 1998).

The finding of baseline-dependent effects has implications for studies of individual differences and clinical application. Recently, the effects of the D2 receptor agonist bromocriptine on cognition were shown in humans to depend on the individual baseline level of working memory performance (Kimberg et al., 1997). This principle might also apply to effects of other monoaminergic agents, including D1 agonists, which are difficult to 
Table 2. Behavioral effect of intra-mPFC SKF $38393(0.06 \mu \mathrm{g} / \mathrm{side})$ or SCH $23390(0.3 \mu \mathrm{g} / \mathrm{side})$ on a fivechoice serial reaction time task

\begin{tabular}{llcl} 
& & $\%$ Omissions & Latency correct $(\mathrm{sec})$ \\
\hline Low baseline & Control vehicle & $12.9 \pm 2.8$ & $0.63 \pm 0.04$ \\
$(n=9)$ & SKF $38393(0.06 \mu \mathrm{g} / \mathrm{side})$ & $7.7 \pm 1.8^{*}$ & $0.60 \pm 0.03$ \\
High baseline & Control vehicle & $11.4 \pm 1.6$ & $0.58 \pm 0.03$ \\
$(n=14)$ & SKF $38393(0.06 \mu \mathrm{g} / \mathrm{side})$ & $12.1 \pm 2.1$ & $0.57 \pm 0.03$ \\
Low baseline & Control vehicle & $10.9 \pm 1.9$ & $0.61 \pm 0.04$ \\
$(n=13)$ & SCH $23390(0.3 \mu \mathrm{g} / \mathrm{side})$ & $12.3 \pm 2.2$ & $0.66 \pm 0.03$ \\
High baseline & Control vehicle & $9.7 \pm 1.8$ & $0.58 \pm 0.03$ \\
$(n=11)$ & SCH $23390(0.3 \mu \mathrm{g} / \mathrm{side})$ & $10.1 \pm 2.3$ & $0.59 \pm 0.03$ \\
\hline
\end{tabular}

Mean \pm SEM values are shown

*Indicates a significant difference compared to control vehicle $(p<0.05)$.

Table 3. Antagonism of the effect of intra-mPFC infusion of SKF $38393(0.06 \mu \mathrm{g} / \mathrm{side})$ by intra-mPFC SCH $23390(1 \mu \mathrm{g} / \mathrm{side})$ on five-choice serial reaction time task

\begin{tabular}{lllcl} 
& & \% Correct & \% Omissions & Latency correct $(\mathrm{sec})$ \\
\hline $\begin{array}{l}\text { Low baseline } \\
(n=5)\end{array}$ & Control vehicle & $69.8 \pm 1.1$ & $9.4 \pm 2.2$ & $0.58 \pm 0.04$ \\
& SKF 38393 $(0.06 \mu \mathrm{g} / \mathrm{side})$ & $79.6 \pm 2.7^{*}$ & $5.8 \pm 2.3$ & $0.58 \pm 0.04$ \\
& SCH $23390(1 \mu \mathrm{g} / \mathrm{side})$ & $72.4 \pm 1.3$ & $10.8 \pm 2.8$ & $0.66 \pm 0.03$ \\
& SKF 38393 $(0.06 \mu \mathrm{g} / \mathrm{side})$ & $71.8 \pm 1.6$ & $12.2 \pm 3.6$ & $0.71 \pm 0.04$ \\
& + SCH $23390(1 \mu \mathrm{g} / \mathrm{side})$ & & & \\
High baseline & Control vehicle & $81.5 \pm 1.0$ & $12.4 \pm 2.1$ & $0.61 \pm 0.04$ \\
$(n=10)$ & SKF 38393 $(0.06 \mu \mathrm{g} / \mathrm{side})$ & $80.1 \pm 1.9$ & $12.5 \pm 2.7$ & $0.61 \pm 0.04$ \\
& SCH 23390 $(1 \mu \mathrm{g} / \mathrm{side})$ & $83.2 \pm 1.3$ & $21.9 \pm 3.8$ & $0.65 \pm 0.05$ \\
& SKF 38393 $(0.06 \mu \mathrm{g} / \mathrm{side})$ & $78.3 \pm 1.9$ & $18.1 \pm 3.2$ & $0.60 \pm 0.03$
\end{tabular}

Mean \pm SEM values are shown

*Indicates a significant difference compared to control vehicle $(p<0.05)$.

\begin{tabular}{llccc}
\hline $\begin{array}{l}\text { Table 4. Behavioral effects of intra-mPFC sulpiride } \\
\text { task }\end{array}$ & & & & \\
& & $\%$ and $\mathbf{3} \boldsymbol{\mu g} / \mathbf{s i d e})$ on a five-choice serial reaction time \\
& & \% Correct & $\%$ Omissions & Latency correct $(\mathrm{sec})$ \\
\hline Low baseline & Control vehicle & $69.6 \pm 1.6$ & $10.3 \pm 3.2$ & $0.63 \pm 0.06$ \\
$(n=4)$ & Sulpiride $(1 \mu \mathrm{g} / \mathrm{side})$ & $77.3 \pm 6.6$ & $7.9 \pm 4.4$ & $0.63 \pm 0.07$ \\
& Sulpiride $(3 \mu \mathrm{g} / \mathrm{side})$ & $76.0 \pm 6.5$ & $10.0 \pm 3.6$ & $0.53 \pm 0.04$ \\
High baseline & Control vehicle & $83.5 \pm 2.3$ & $11.2 \pm 2.1$ & $0.54 \pm 0.02$ \\
$(n=8)$ & Sulpiride $(1 \mu \mathrm{g} / \mathrm{side})$ & $78.8 \pm 4.6$ & $9.1 \pm 1.7$ & $0.57 \pm 0.04$ \\
& Sulpiride $(3 \mu \mathrm{g} / \mathrm{side})$ & $79.2 \pm 3.2$ & $8.0 \pm 1.2$ & $0.50 \pm 0.02$ \\
\hline
\end{tabular}

Mean \pm SEM values are shown. There were no significant differences.

study selectively in humans at present (Muller et al., 1998). The possibility that baseline differences in performance on different types of task, interacting with factors such as arousal, stress (cf. Zahrt et al., 1997), and motivational factors, might affect the way in which cognition is modulated by dopamine receptor agents may be an important principle in determining possible therapeutic effects of such agents in many clinical disorders. Thus, based on what is already known about effects of dopaminergic treatment of neuropsychiatric and neurological disorders, the results could be relevant, for example, to cognitive deficits in schizophrenia (Zahrt et al., 1997), Parkinson's disease (Lange et al., 1992), attention-deficit hyperactivity disorder (Arnsten 1998), and acute brain injury (McDowell et al., 1998).

\section{REFERENCES}

Arnsten AFT (1997) Catecholaminergic regulation of the prefrontal cortex. J Psychopharmacol 11:151-162.
Arnsten AFT (1998) Catecholamine modulation of prefrontal cortical cognitive function. Trends Cognit Sci 2:436-447.

Arnsten AFT, Cai JX, Murphy BL, Goldman-Rakic PS (1994) Dopamine D1 receptor mechanisms in the cognitive performance of young adult and aged monkeys. Psychopharmacology (Berl) 116:143-151.

Baunez C, Robbins TW (1999) Effects of dopamine depletion of the dorsal striatum and further interaction with subthalamic nucleus lesions in an attentional task in the rat. Neuroscience 92:1343-1356.

Bischoff S, Heinrich M, Krauss J, Sills MA, Williams M, Vassout A (1988) Interaction of the D1 receptor antagonist SCH 23390 with the central 5-HT system: radioligand binding studies, measurements of biochemical parameters and effects on L-5-HTP syndrome. J Recept Res 8:107-120.

Briggs CA, Pollock NJ, Frail DJ, Paxson CL, Ralowski RF, Kang CH, Kebabian JW (1991) Activation of the 5-HT1c receptor expressed in Xenopus oocytes by the benzazepines SCH 23390 and SKF 38393. Br J Pharmacol 104:1038-1044.

Brozoski T, Brown RM, Rosvold HE, Goldman PS (1979) Cognitive deficit caused by regional depletion of dopamine in prefrontal cortex of rhesus monkey. Science 205:929-931.

Carli M, Robbins TW, Evenden JL, Everitt BJ (1983) Effects of lesions 
to ascending noradrenergic neurones on performance of a 5-choice serial reaction task in rats: implications for theories of dorsal noradrenergic bundle function based on selective attention and arousal. Behav Brain Res 9:361-380.

Cole BJ, Robbins TW (1989) Effects of 6-hydroxydopamine lesions of the nucleus accumbens septi on performance of a 5-choice serial reaction time task in rats: implications for theories of selective attention and arousal. Behav Brain Res 33:165-179.

Collins P, Roberts AC, Dias R, Everitt BJ, Robbins TW (1998) Perseveration and strategy in a novel spatial self-ordered sequencing task for non-human primates: effects of excitotoxic lesions and dopamine depletions of the prefrontal cortex. J Cognit Neurosci 10:332-354.

Duvauchelle CL, Fleming SM, Kornetsky C (1998) Prefrontal cortex infusions of SCH 23390 cause immediate and delayed effects on ventral tegmental area stimulation reward. Brain Res 811:57-62.

Gong L, Kostrzewa RM, Fuller RW, Perry KW (1992) Supersensitization of the oral response to SKF 38393 in neonatal 6-OHDA-lesioned rats is mediated through a serotonin system. J Pharmacol Exp Ther 261:1000-1007.

Granon S, Poucet B, Thinusblanc C, Changeux JP, Vidal C (1995) Nicotinic and muscarinic receptors in the rat prefrontal cortex-differential roles in working-memory, response selection and effortful processing. Psychopharmacology 119:139-144.

Kimberg DY, D'Esposito M, Farah MJ (1997) Effects of bromocriptine on human subjects depends on working memory capacity. NeuroReport 8:3581-3585.

Lange K, Robbins TW, Marsden CD, James M, Owen A, Paul GM (1992) L-Dopa withdrawal selectively impairs performance in tests of frontal lobe function in Parkinson's disease. Psychopharmacology 107:394-404.

McDowell S, Whyte J, D'Esposito M (1998) Differential effect of a dopaminergic agonist on prefrontal function in traumatic brain injury patients. Brain 121:1155-1164.

Millan MJ, Dekeyne A, Gobert A (1998) Serotonin (5-HT) 2 C receptors tonically inhibit dopamine (DA) and noradrenaline (NA), but not $5-\mathrm{HT}$, release in the frontal cortex in vivo. Neuropharmacology 37:953-955.

Muir JL, Robbins TW, Everitt BJ (1994) AMPA-induced lesions of the basal forebrain: a significant role for the cortical cholinergic system in attentional function. J Neurosci 14:2313-2326.

Muir JL, Everitt BJ, Robbins TW (1996) The cerebral cortex of the rat and visual attentional function: dissociable effects of mediofrontal, cingulate, anterior dorsolateral and parietal cortex lesions on a five choice serial reaction time task in rats. Cereb Cortex 6:470-481.

Muller U, von Cramon DY, Pollmann S (1998) D1 - versus D2 - receptor modulation of visuospatial working memory in humans. J Neurosci 18:2720-2728.

Murphy BL, Arnsten AFT, Goldman-Rakic PS, Roth RH (1996a) Increased dopamine turnover in the prefrontal cortex impairs spatial working memory performance in rats and monkeys. Proc Natl Acad Sci USA 93:1325-1329.

Murphy BL, Arnsten AFT, Jentsch JD, Roth RH (1996b) Dopamine and spatial working memory in rats and monkeys: pharmacological reversal of stress-induced impairment. J Neurosci 16:7768-7775.

Ohlstein EH, Berkowitz BA (1985) SCH 23390 and SKF 83566 are antagonists at vascular dopamine and serotonin receptors. Eur J Pharmacol 108:205-208.

Paxinos G, Watson C (1982) The rat brain in stereotaxic coordinates. Australia: Academic.
Pehek EA (1996) Local infusion of the serotonin antagonists ritanserin or ICS 205,930 increases in vivo dopamine release in the rat medial prefrontal cortex. Synapse 24:12-18.

Pehek EA, Bi Y (1997) Ritanserin administration potentiates amphetamine-stimulated dopamine release in the rat prefrontal cortex. Prog Neuropsychopharmacol Biol Psychiatry 21:671-682.

Plech A, Brus R, Kalbfleisch, Kostrzewa RM (1995) Enhanced oral activity to intrastriatal SKF 38393 and $\mathrm{mCPP}$ are attenuated by intrastriatal mianserin in neonatal 6-OHDA-lesioned rats. Psychopharmacology 119:466-473.

Robbins TW (1985) Neuropsychological evaluation of higher cognitive function in animals and man: can psychopharmacology contribute to neuropsychology? In: Psychopharmacology: recent advances and future prospects (Iversen SD, ed) pp 155-169. Oxford: Oxford UP.

Robbins TW (1998) The psychopharmacology and neuropsychology of attention in experimental animals. In: The attentive brain (Parasuraman R, ed) pp 189-200, Cambridge, MA: MIT.

Robbins TW, Everitt BJ (1995) Arousal systems and attention. In: The cognitive neurosciences (Gazzaniga M, ed), pp 703-720. Cambridge, MA: MIT.

Robbins TW, Roberts AC, Owen AM, Sahakian BJ, Everitt BJ, Wilkinson LS, Muir JL, De Salvia M, Tovee M (1993) Monoaminergicdependent cognitive functions of the prefrontal cortex in monkey and man. In: Prefrontal cortex (Christen Y, ed), pp 95-111. Heidelberg: Springer.

Robbins TW, Granon S, Muir JL, Durantou F, Harrison A, Everitt BJ (1998) Neural systems underlying arousal and attention. In: Cocaine: effects on the developing brain (Harvey JA, Kosofsky BE, eds). Ann NY Acad Sci 846:222-237.

Roberts AC, De Salvia MA, Wilkinson LS, Collins P, Muir JL, Everitt BJ, Robbins TW (1994) 6-hydroxydopamine lesions of the prefrontal cortex in monkeys enhance performance on an analogue of the Wisconsin Card Sorting test: possible interactions with subcortical dopamine. J Neurosci 14:2531-2544.

Sahakian BJ, Sarna GS, Kantamaneni BD, Jackson A, Hutson PH, Curzon G (1985) Association between learning and cortical catecholamines in non-drug-treated rats. Psychopharmacology 86:339-343.

Sawaguchi T, Goldman-Rakic PS (1991) D1 dopamine receptors in prefrontal cortex: involvement in working memory. Science 251:947-950.

Schmidt CJ, Fadayel GM (1995) The selective 5-HT $2 \mathrm{~A}$ receptor antagonist, MDL 100,907, increases dopamine efflux in the prefrontal cortex of the rat. Eur J Pharmacol 273:273-279.

Seamans JK, Floresco SB, Phillips AG (1998) D1 receptor modulation of hippocampal-prefrontal cortical circuits integrating spatial memory with executive control functions in the rat. J Neurosci 18:1613-1621.

Simon H (1981) Dopaminergic A10 neurons and the frontal system. J Physiol (Paris) 77:81-95.

Vezina P, Blanc G, Glowinski J, Tassin J-P (1994) Blockade of D-1 dopamine receptors in the medial prefrontal cortex produces delayed effects on pre- and postsynaptic indices of dopamine function in the nucleus accumbens. Synapse 16:104-112.

Williams GV, Goldman-Rakic (1995) Modulation of memory fields by dopamine D1 receptors in prefrontal cortex. Nature 376:572-575.

Yang CR, Seamans JK (1996) Dopamine D1 receptor actions in layers V-V1 rat prefrontal cortex neurons in vitro: modulation of dendriticsomatic signal integration. J Neurosci 16:1922-1935.

Zahrt J, Taylor JR, Mathew RG, Arnsten AFT (1997) Supranormal stimulation of D1 dopamine receptors in the rodent prefrontal cortex impairs working memory performance. J Neurosci 17:8528-8535. 